\title{
Joanna de Sá: medicina, política e moral nas páginas de $\boldsymbol{O}$ Monitor*
}

\section{Joanna de Sá: medicine, politics and morality in the pages of $\mathrm{O}$ Monitor}

\author{
Vera Nathália Silva de Tarso \\ Professora da Faculdade de Tecnologia e Ciências \\ Educação a Distância \\ Rua Conselheiro Saraiva, $147,6^{\circ}$ andar \\ 40255-370 - Salvador - BA - Brasil \\ veranathalia@gmail.com
}

Recebido para publicação em maio de 2007. Aprovado para publicação em setembro de 2008.
TARSO, Vera Nathália Silva de. Joanna de Sá: medicina, política e moral nas páginas de O Monitor. História, Ciências, Saúde - Manguinhos, Rio de Janeiro, v.15, n.4, out.-dez. 2008, p.973-988.

\section{Resumo}

Fruto da luta da classe médica e dos interesses do Estado em resolver uma grave questão de saúde pública, o asilo de alienados baiano São João de Deus foi inaugurado em junho de 1874 , cercado de otimismo e confiança por parte de todos os envolvidos.

Entretanto sua história logo tomaria rumo inesperado quando a gravidez e o parto de uma interna envolveram a Santa Casa de Misericórdia, o Estado e a imprensa num emaranhado de interesses e conflitos, revelando que a realidade de uma instituição asilar estava muito longe das pretensões de seus idealizadores. No momento em que a psiquiatria baiana começava a dar seus primeiros passos, o caso lançou sérias dúvidas quanto à capacidade de essa medicina assumir integralmente a responsabilidade pelo tratamento da loucura.

Palavras-chave: psiquiatria; mulher; Bahia (Brasil); século XIX.

\section{Abstract}

Fruit of the struggle of the medical profession and the interests of the State in resolving a serious public health question the Bahian São João de Deus asylum for the alienated was inaugurated in June 1874 , surrounded by the optimism and confidence of everyone involved.

Meanwhile, its history would soon take an unexpected direction when the pregnancy and birth of an internee involved the Santa Casa de Misericórdia, the State and the press in an entangled web of interests and conflicts, revealing that the reality of an asylum institution was far from that imagined by its creators. At a time when Bahian psychiatry was beginning to take its first steps, the case produced serious doubts regarding the capacity of this medicine to wholly assume responsibility for the treatment of insanity.

Keywords: psychiatry; women; Bahia (Brazil); 19 ${ }^{\text {th }}$ century. 


\section{A quinta do solar}

$\mathrm{N}^{2}$

o dia 24 de junho de 1874, autoridades eclesiásticas, civis e militares seguiram para a freguesia de Brotas, uma das maiores e mais importantes da capital da província da Bahia, para a inauguração do Asilo de Alienados de São João de Deus. Representando a Santa Casa de Misericórdia da Bahia, que administraria o asilo, seu provedor Manuel Pinto de Souza Dantas proferiu um discurso emocionante, segundo a Gazeta Medica da Bahia na sua edição de 31 de julho de 1874, no qual evocou "todas as ideias que devião pairar sobre a magestade daquella instituição". Após receber as bênçãos em missa solene, realizada às 11 horas da manhã pelo capelão da Santa Casa, padre Leôncio Izidoro de Souza, os presentes testemunharam, emocionados, a chegada dos primeiros internos que, de braços dados com os irmãos da Santa Casa, adentraram as dependências do asilo.

Depois da instalação do retrato do provedor Souza Dantas no salão principal, o chefe de polícia, o comandante geral das armas e outras autoridades percorreram as instalações do asilo, "decentemente ornados e preparados convenientemente, como era de esperar". Profundamente impressionado com as instalações físicas do asilo, o jornalista do Diário da Bahia, de onde a Gazeta Medica reproduz a notícia, destacou o asseio do estabelecimento, os leitos colocados "na melhor ordem", a botica, a cozinha, a despensa, tudo revelando o "zelo inexcedível, o cuidado providente e o pensamento altamente humanitário da digna Mesa da Santa Casa". No discurso de Demétrio Cyriaco Tourinho, médico diretor do Asilo São João de Deus, este tinha como missão "recolher os que em transe doloroso da vida foilhes a razão cercada de trevas", recebendo-os com a esperança "de que a luz do céu, a luz da caridade, e a luz da sciencia venhão restituir-lhes a luz da razão". ${ }^{1}$

A abertura do asilo de alienados na capital baiana foi saudada como uma vitória da civilização e da ciência sobre a barbárie que relegava aos loucos as masmorras e celas da Casa de Correção ou os quartos insalubres do hospital de São Cristóvão, nos quais a mesma Santa Casa recolhia os loucos. Para os médicos baianos era uma vitória resultante das articulações da classe médica com o universo político baiano, representada pelos médicos e políticos Demétrio Tourinho e José Luiz de Almeida Couto, que levaram à aprovação da verba orçamentária em 1863 destinada à criação do Asilo.

No dia 13 de julho de 1874, menos de um mês depois da abertura do Asilo, foi admitida Joanna Virginia Autran e Sá, filha de Jacintho Alves de Sá, negociante e irmão da Santa Casa de Misericórdia. ${ }^{2}$ As fontes não revelam por que Joanna de Sá foi internada. A primeira notícia a respeito dela, já como pensionista do asilo, provém de seu registro no primeiro relatório de Demétrio Cyriaco Tourinho, diretor do São João de Deus, ao provedor da Santa Casa em 1875. Ali o nome de Joanna aparece junto aos demais 81 internos recolhidos no primeiro ano de funcionamento do Asilo. ${ }^{3}$ Diagnosticada como portadora de mania aguda $^{4}$, sua rotina no São João de Deus era marcada pela terapêutica alienista e pelo regulamento geral.

A passagem de Joanna de Sá pelo São João de Deus poderia permanecer despercebida como a de tantas outras mulheres e homens que entraram, foram tratados e saíram curados ou não, vivos ou não, do único asilo público para tratamento de alienados da Bahia no século XIX ${ }^{5}$, não fosse seu tio e curador, Henrique Autran da Matta e Albuquerque, ter levado ao 
conhecimento do presidente da província o fato ocorrido em 17 de setembro de 1877. Em carta confidencial, denunciou uma tragédia pessoal e atacou ferozmente o asilo onde sua sobrinha estava recolhida. A partir daí, Joanna de Sá deixou de ser mais uma interna e tornou-se o pivô da mais grave crise que o Asilo sofreu enquanto esteva sob a administração da Santa Casa.

Atento ao que acontecia, um jornal da capital baiana, O Monitor, abriu espaço nas suas edições diárias para o caso, revelando para a opinião pública os pormenores do que se passara atrás dos muros altos do Asilo e nos gabinetes das autoridades envolvidas. O ocorrido foi usado para reforçar ainda mais sua posição de adversário da administração do São João de Deus, alvo de críticas freqüentes nos editoriais e em notícias, a exemplo daquela publicada em 31 de outubro de 1877, no auge da crise envolvendo Joanna de Sá. A matéria em questão relatava a fuga de um interno que acabara atacando uma residência nas Pitangueiras, a poucos metros do São João de Deus. Sob o título "Nova fuga de doudos", chamava a atenção para as fugas freqüentes, contra as quais pedia "sérias e efficazes providencias", acusando de negligente e omissa com a opinião pública a direção do Asilo, que nem se dera o trabalho de informar à população sobre as providências que tomaria para que tais fatos deixassem de ocorrer com tamanha e assustadora regularidade. Afirmava ainda que "se o asylo não pode conter seus hospedes, confessa-se incapaz de continuar". ${ }^{6}$

Assim, o escândalo denunciado pelo médico Henrique da Matta e Albuquerque caiu como uma luva para um diário ávido de motivos para atacar o asilo baiano e hábil na divulgação da história junto a seus leitores.

\section{Sobe o pano}

No dia 10 de outubro de 1877, o editorial "Os últimos acontecimentos na Misericordia", de $O$ Monitor, destacava as mudanças administrativas que estavam ocorrendo no asilo da Boa Vista de Brotas. Informava que, além das nomeações do médico José de Teive e Argollo para o cargo de administrador e José Francisco da Silva Lima para médico do asilo ${ }^{7}$, já conhecidas dos seus leitores, outras estavam por ocorrer. Em clima de suspense, o artigo prometia futuros comentários sobre os últimos acontecimentos, "que não podião caber todos nos limites de um só artigo...". ${ }^{8}$

Na edição seguinte, de 11 de outubro, o jornal publicou um editorial de primeira página ${ }^{9}$, no qual comentou outras mudanças pelas quais o asilo havia passado nas últimas semanas: a demissão da primeira enfermeira, "sob cuja inspecção e direcção corriam varios serviços internos"; a exoneração do médico adjunto ${ }^{10}$, cargo ainda vago; a separação dos serviços médico, administrativo e econômico, "que ate agora estavam reunidos nas mãos do medicodirector"; e o pedido de demissão do próprio médico diretor Demétrio Cyriaco Tourinho, em $1^{\circ}$ de outubro de $1877 .{ }^{11} \mathrm{O}$ jornal indagava sobre a causa de tantas mudanças e destacava a saída de Tourinho, aquele que, segundo o editorialista, "desde a fundação do Asylo alli esteve a gozar de plena confiança dos mordomos e do provedor"12 e que estranhamente saíra "sem uma palavra de louvor, sem se consignar na acta um voto de sentimento, sem um aperto de mão, sem um adeus sequer".

O Monitor não foi o único jornal que voltou sua atenção para as reestruturações administrativas por que passava o São João de Deus. O Alabama, outro jornal de Salvador, 
publicou um artigo especial em 18 de agosto de 1877, cujas duras críticas causaram um pedido de esclarecimentos por parte do provedor da Santa Casa, Francisco Rodrigues da Silva, ao mordomo do Asilo, Antonio de Cerqueira Pinto. No seu oficio de 22 de agosto, o provedor pediu, "com urgencia", que o mordomo lhe oficiasse esclarecendo as informações levadas a público pelo artigo do jornal. ${ }^{13}$

O que estaria acontecendo de tão grave na instituição, a ponto de a imprensa abordar com tanta freqüência a Boa Vista de Brotas? Evidentemente todo o otimismo nos noticiários e discursos, quando da inauguração do São João de Deus, ao confrontar-se com a realidade da assistência aos doentes mentais da província (e até de fora), desaparecera ou dera dar lugar às imensas dificuldades em que o asilo vivia mergulhado. Mesmo assim, o que poderia ter despertado tamanho interesse?

A resposta estava com Henrique Autran da Matta e Albuquerque, em sua carta confidencial que chegou às mãos do presidente da província Henrique de Lucena, em 17 de setembro de 1877. Nela, o médico denunciava o "misero estado" do Asilo São João de Deus, "pelo relaxamento e immoralidades ali cometidas". O longo documento começava com um relato do que acontecera na tarde de 14 de setembro, quando Antonio de Souza Gouveia $^{14}$ veio à sua casa comunicar que sua cunhada Joanna de Sá, sobrinha de Henrique Autran e irmã de sua mulher Gertrudes, recolhida desde 1874 no São João de Deus "havia sido deflorada, e representando achar-se com sete mezes, pouco mais ou menos de gravidez!".

Tomado de surpresa pela notícia, Henrique Autran resolveu conferir sua veracidade e dirigiu-se, junto com o também médico Antonio Gouveia, para o São João de Deus. Ao chegarem ao asilo, ambos foram recebidos pelo farmacêutico Arthur Pinheiro, que lhes franqueou o quarto de Joanna. Para horror de Autran, a moça encontrava-se deitada, despida, numa cama de ferro sobre um colchão e tinha apenas uma coberta de chita a cobrir-lhe o corpo. Depois de pedirem que uma enfermeira vestisse Joanna, Henrique e Antonio passaram a examiná-la e reconheceram estar a alienada com sete meses de gravidez. Logo depois ambos interrogaram o farmacêutico sobre "quem seria o autor desse acto tão immoral" e receberam como resposta que julgavam ter sido "um alienado já fallecido". Henrique, para quem o defloramento e a gravidez de Joanna de Sá mostravam que não havia "ali moralidade alguma, nem tão pouco a vigilancia necessaria", responsabilizou moralmente o médico diretor do Asilo, Demétrio Tourinho, pelo ocorrido. Ao final da carta, pedia ao presidente da província que ordenasse ao juiz de órfãos as "providências enérgicas contra o culpado ou culpados d'esse acto criminoso e immoral".$^{15}$

É compreensível o horror de Henrique Albuquerque, mas surpreende que a família de Joanna tenha levado tanto tempo para descobrir sua gravidez, já que o regulamento permitia visitas aos alienados aos domingos, das oito às 11 da manhã e das três às cinco da tarde, além das quintas-feiras, reservadas exclusivamente aos familiares. ${ }^{16}$ Supomos que a família de Joanna pouco a procurava no Asilo e por isso não percebeu o que estava acontecendo. A causa desse abandono não podemos saber, mas não era a doença de Joanna. Embora seja dito por Tourinho que ela tinha constantes acessos de fúria, quando rasgava as roupas, em outras ocasiões seu comportamento era pacífico o suficiente para conviver até mesmo com a família do médico-diretor do Asilo, conforme afirmou o enfermeiro José Messias Badaró, em depoimento no inquérito policial instaurado. Sendo possível a Joanna passar 
dias em companhia dos filhos de Demétrio Tourinho em sua roça, nas imediações do São João de Deus, o que impedia que sua família a visitasse no asilo?

Apesar de seus pais não serem mais vivos, Joanna tinha quatro irmãos: Maria Francisca, Jacintho, Gertrudes e Francisca Maria. Não que Joanna precisasse da família. Órfã de mãe desde os 11 anos, quando foi internada em 1874 Joanna também já havia perdido seu pai, Jacinto Alves de Sá, que morrera em 1864. Sua mãe, dona Gertrudes Autran da Matta e Sá, falecera em 24 de agosto de 1857. Aos 11 anos, então, Joanna recebera, ao final do inventário, ${ }^{17}$ encerrado em 1863, um sobrado nas Mercês e 6:338\$900 reis, meios suficientes para sustentá-la fora do seio da família.

Embora não haja um relato direto sobre os motivos que levaram a família a se esquecer de Joanna no São João de Deus, é possível tecer algumas conjecturas. Além de órfã, Joanna não era, digamos, uma autêntica representante da mais fina flor da aristocracia baiana. Solteira, morava sozinha e trabalhava como costureira, sustentando-se com seu próprio trabalho e morando longe da tutela familiar. Mais ainda: Joanna foi acusada, pelo diretor do Asilo, de "andar vagabunda pela cidade" atrás de estrangeiros, com quem mantinha "paixões amorosas", sendo "publico e notorio" que ela vivia "fora das vistas de seos parentes", morando sozinha numa casa sua à ladeira do Sodré, envolvendo-se romanticamente com "estrangeiros". 18

Teria Joanna se afastado da família, ou esta se afastado de Joanna? É possível que sua conduta pouco usual tenha levado ao afastamento da família como também à sua internação no asilo de alienados, já que desde o final do século XVII a medicalização do corpo feminino, apoiada pelas novas descobertas da medicina e da biologia, associou o exercício saudável da sexualidade feminina à reprodução, restrita ao papel de mãe e dentro do casamento, e mesmo as menores transgressões do comportamento sexual feminino, antes moralmente aceitas, passaram a ser classificadas como doenças.

Quer tenha sido internada por conta de sua vida 'desregrada' ou por qualquer outro motivo, Joanna de Sá representa uma população asilar feminina predominante no São João de Deus desde sua inauguração. As mulheres eram maioria nas admissões e minoria nas altas, e permaneciam recolhidas à instituição médica por mais tempo que os homens. Para a medicina mental da época isso não era raro, afinal, consideravam os médicos, a vulnerabilidade às doenças mentais era bem maior nas mulheres. Donas de particularidades anatômicas e fisiológicas que levariam a uma instabilidade crônica de seu sistema nervoso, elas padeceriam muito mais de problemas nervosos que o sexo oposto. Portanto enquanto o alienismo ainda tateava entre as teorias organicistas e vitalistas a respeito das causas da doença mental, no caso da mulher a resposta já parecia ter sido encontrada: o problema estava no seu corpo, num sistema nervoso diretamente ligado a um sistema reprodutivo que vivia em constante transformação.

De que outra forma explicar os distúrbios que acometiam as mulheres durante a menstruação, a gravidez, o puerpério e a menopausa? A resposta só poderia estar na instabilidade desse corpo. Para desvendá-lo, a ciência elegeu o corpo feminino seu objeto mais privilegiado. A partir de finais do século XVIII até o início do século XX, muito foi escrito a respeito dessa natureza feminina instável, em permanente mutação, e inaugurouse um grande debate sobre a chamada 'questão da mulher', seu papel e sua natureza. Para 
Elisabeth Vieira (2002), desde aquele momento o corpo da mulher tornou-se absolutamente medicalizado, tornando-se objeto privilegiado da medicina e dos doutores, num processo de afastamento das próprias mulheres em relação a seus corpos. Ainda segundo a autora, esse processo estava diretamente vinculado à necessidade de cuidar da reprodução e manutenção da saúde da população, no momento de emergência das sociedades capitalistas e dos Estados nacionais no Velho Mundo. Ao ver a mulher como elemento fundamental nesse processo, a medicina voltou-se para o interior dos lares com a função de conhecer esse corpo a quem incumbia gerar e manter a vida.

Ao analisar o surgimento da obstetrícia e da ginecologia no Brasil, Ana Paula Vosne Martins (2000) argumenta que o interesse da ciência moderna pelo corpo feminino deve ser articulado com a racionalidade científica que impulsionava o homem para o descobrimento de novos saberes e a reavaliação de velhas crenças. O espírito científico que se debruçava no mundo natural e buscava descobrir suas leis fazia o mesmo com o corpo feminino. Do movimento de desbravamento deste, que se iniciou nesse período, surgiram, no século XIX, a ginecologia e a obstetrícia, especialidades médicas voltadas exclusivamente para o trato do corpo da mulher.

O mesmo espírito científico elegeu a razão como determinante da condição humana. A contraposição entre racionalidade e sensibilidade levou a uma oposição entre homens e mulheres, enquadrados em modelos rígidos nos quais as mulheres passavam a ser vistas como seres cujo exercício da razão era deficiente, quando não inexistente. Definida como 'emocional', em contraposição ao homem racional, a mulher tornou-se algo a ser controlado e submetido a extrema observação, para que seu descontrole não afetasse a organização da nova sociedade. A razão feminina não tinha autonomia justamente por ser frágil, fraca, limitada. Caberia aos homens reeducar as mulheres, seres de paixões desenfreadas e sem limites, preparando-as para um novo papel social, no qual sua dependência do masculino seria constante, pois elas não poderiam caminhar sozinhas.

É interessante porém perceber que, mesmo imbuídos do espírito científico, quando requeriam internamento para suas alienadas, continuavam presentes nos discursos de familiares, delegados, clérigos e juízes antigas representações da loucura. As particularidades que a insanidade feminina adquiriu no discurso dessa medicina mental refletem claramente representações ancestrais sobre o corpo e a sexualidade femininos. O grande diferencial, então, era a cientificidade que o revestia e que, segundo Clementina Cunha (1986), tornavao agora quase incontestável.

De acordo com Cunha (1986), o saber alienista consolidou a representação da mulher como um ser determinado por seus ciclos biológicos, um ser estranho, imprevisível, dono de um corpo inquieto e inquietante, da puberdade até a menopausa. Espaço natural para o florescimento da loucura, o organismo feminino seria a causa que predisporia as mulheres à doença mental, sendo processos fisiológicos naturais como menstruação, gravidez e parto particularmente priorizados pelos alienistas e psiquiatras na definição e no diagnóstico das doenças mentais que afetavam as mulheres.

Carla Cristina Garcia (1995) utiliza-se da mitologia e de representações de loucas na literatura de Virginia Woolf e Sylvia Plath, para discutir a insanidade feminina entre o século XIX e o XX, e considera decisiva a noção de gênero para os diagnósticos, as definições 
e os tratamentos da insanidade. Para a autora, "os modelos psiquiátricos masculinos tornaram-se modelos culturais, e tanto a teoria psiquiátrica quanto a vigilância da moral pública transformaram a diferença entre os gêneros e a loucura numa enfermidade feminina" (p.51). No dizer dos médicos, as mulheres eram de uma instabilidade preocupante.

As relações entre psiquiatria e feminilidade pautavam-se por uma extrema preocupação com o papel social da mulher, um ser "moral e socialmente perigoso", cuja fisiologia específica a predisporia para a instabilidade nervosa, "o bem e o mal, a virtude e a degradação", e que por isso precisava de controle para cumprir adequadamente seu papel social de esposa e mãe (Engel, 2001). As mulheres eram quase sempre internadas por distúrbios acontecidos no seu desempenho no âmbito doméstico, e mesmo que existissem diferenças de "classe, de níveis de opressão e consciência quanto à sua condição, de instrução e de experiência pessoal e social", o que perpassava a história dessas internas era "ter nascido mulher em uma cultura e em uma circunstância histórica em que este simples e fortuito evento é, de per si, tomado como uma deficiência" (Cunha, 1986, p.144).

Teriam sido então as alegadas transgressões que levaram para o São João de Deus sua interna mais célebre? Centro do maior escândalo que o Asilo enfrentou na sua primeira etapa de funcionamento, Joanna Virginia Autran e Sá foi comparada a mulheres de vida livre por Demétrio Tourinho e outros envolvidos no caso. Esquecida pela família no São João de Deus, Joanna Virginia saiu do esquecimento por conta de uma gravidez inesperada que enredou nas suas investigações a Misericórdia, o Asilo e o governo provincial.

\section{Em busca de respostas}

Enquanto a família tentava absorver a má noticia, o presidente da província Henrique de Lucena enviou ao provedor da Santa Casa uma cópia da carta, junto a um ofício no qual pedia esclarecimentos das denúncias nela contidas, "ouvindo o Director e Medico do Asylo de São João de Deus". ${ }^{19}$ Assim foi feito, e a ordem do provedor foi cumprida em 19 de setembro de 1877, quando Demétrio Cyriaco Tourinho oficiou ao mordomo do Asilo São João de Deus a respeito do conteúdo da carta confidencial de Henrique Autran. Dizendose surpreso e espantado, Tourinho acusou Henrique Autran de faltar com a verdade em muitos pontos de sua carta e de ter opinião "muito parcial e muito avessa" à existência do São João de Deus, o que o obrigava a refutá-lo, não só em sua defesa, mas também na do Asilo, do qual era médico e diretor desde sua criação.

Disse que deplorava o fato "mais que ninguém" pelo dano causado à moralidade do estabelecimento, mas que reconhecia que o acontecido "foi de tal ordem que impossível fora prever". ${ }^{20}$ Rebateu as acusações de "relaxado" e "immoral", feitas por Henrique Autran, dizendo que "nenhum facto, nenhum acontecimento até agora, a excepção deste, todo fortuito, ainda se deo neste estabelecimento que autorise as espressões tão ásperas e inconvenientes d'aquelle Dr". Quanto à nudez de Joanna, disse que a interna, "que tem accessos de mania", dilacerava com freqüência seus vestidos. Mesmo o exame feito em Joanna é questionado. Ao certificar-se de que Joanna estava grávida, Tourinho recorreu ao barão de Itapoan - renomado parteiro cujo parecer seria praticamente inquestionável para examiná-la. O médico atestou uma gravidez de seis meses e não de sete, como afirmaram 
Henrique Autran e Antonio Gouveia. Quanto ao defloramento de Joanna ter ocorrido nas dependências do Asilo, Demétrio rebateu com a conclusão do barão de Itapoan de que Joanna de Sá não era primípara. Para Demétrio, Henrique Autran procurava fazer cair sobre a administração do São João de Deus uma responsabilidade maior do que cabia à instituição. $^{21}$

No mesmo dia 19 de setembro de 1877, o provedor da Santa Casa, Francisco Rodrigues da Silva, oficiou ao presidente da província, dando-lhe ciência de que havia dado ordens "as mais terminantes" para que se iniciasse, no Asilo, "um rigoroso inquerito sobre tão lamentável incidente". ${ }^{22}$ Três dias depois, em 22 de setembro, o provedor enviou ao juiz de órfãos, João Ladislau Japi-Assu de Figueiredo e Mello, um ofício respondendo às indagações deste a respeito da gravidez de Joanna. Afirmava ser verídica a notícia da gravidez da alienada, mas que não estava provado que tivesse sido ela deflorada no Asilo. Qualificava o caso de "lamentavel ocorrência" e assegurava que um inquérito rigoroso prosseguia no São João de Deus, "senão para reparar o mal, que é irremediavel, ao menos para punir quem foi delle causador". ${ }^{23}$

Realmente, a investigação interna corria: em 22 de setembro, o provedor pediu, em ofício ao barão de Itapoan, detalhes sobre o exame realizado em Joanna dias antes, ao que respondeu o médico dois dias depois afirmando que, "de accordo com os meios de investigações aconselhados pela sciencia e com os signaes por elles fornecidos em taes casos", Joanna de Sá encontrava-se grávida, sendo a "epocha provável da prenhez" de seis a sete meses, não sendo ela primípara. ${ }^{24}$

No dia 8 de outubro, o provedor sentiu-se informado a ponto de responder ao presidente da província sobre as acusações de Henrique Autran. Repetiu-lhe o que havia dito ao juiz de órfãos, que era "infelizmente verdade" estar Joanna de Sá grávida, mas, tentando diminuir a importância do fato, afirmava que acontecimentos desse tipo não eram de todo estranhos a hospícios de alienados, onde os internos, com astúcia e sagacidade, conseguiam iludir os empregados, os quais, mesmo experientes e vigilantes, não conseguiam coibir atos de "inaudita atrocidade, que repugnão, a natureza e dignidade humana". Sendo assim, classificar a administração do São João de Deus de relaxada e imoral, como fizera Henrique Autran, era um exagero: se tais ocorrências se davam em asilos da Europa, quiçá aqui na Bahia, onde o São João de Deus, nos seus "tres annos de difficil e atribulada existência", lutava contra a deficiência de recursos. Num gesto de compreensão, o provedor perdoou Henrique Autran e seus "epítetos". Para ele, sua dor, "que surprehendeu-o pela dupla desdita de sua sobrinha", tomou-lhe a serenidade, levando-o à "inconveniência e aspereza d'aquellas frases", e que "serenadas as paixões que num momento turvarão-no", reconhecerá a injustiça de suas palavras. Perguntava-se se tal tragédia poderia ter sido evitada. Sim, respondia, caso houvesse sido implantada a completa separação dos sexos, muito pedida pelo médico diretor Demétrio Tourinho 25 , seguindo o modelo dos "países civilizados". Porém, "onerada de despesas pelos muitos serviços que mantem, e da divida enorme d'aquelle asylo", a Santa Casa ainda não conseguira implantar semelhante medida, necessária para que internos e internas não cedessem ao impulso das "paixões carnaes que irrompem indomáveis n'aquelles infelizes" ${ }^{26}$ Francisco Rodrigues da Silva fazia ainda uma veemente defesa de Demétrio Cyriaco Tourinho, justificando seu silêncio sobre o caso, 
pois "maiores serião os inconvenientes dessa revelação do que os da prudente reserva e expectativa em que se manteve aquelle funccionário", que em mais de três anos à frente do asilo São João de Deus prestara relevantes serviços ao asilo, dando à Santa Casa "as mais decididas provas de confiança" e cujo "profundo pesar" que o caso lhe causara o levara a pedir demissão no dia primeiro de outubro. Encerrando o ofício, comunicou o nascimento, no dia anterior, sete de outubro, do bebê de Joanna, uma criança do sexo feminino que ainda se encontrava no Asilo, tendo sido tomadas, garantia o provedor, "todas as providencias para assegurar o bem estar e futuro dessa criancinha". ${ }^{27}$

É provável que a Santa Casa da Misericórdia e seu provedor tenham considerado o caso encerrado com esse ofício e suas explicações, que não chegaram a apontar ninguém como responsável pela gravidez de Joanna. Entretanto o governo da província e o juiz de órfãos não se deram por satisfeitos com a sindicância interna da instituição. A insatisfação do juiz de órfãos levou a inquérito policial, e na Presidência da Província a pouca atenção da Provedoria da Santa Casa para com o caso teve conseqüências bem mais sérias.

\section{A comissão do governo}

A 13 de outubro de 1877 o presidente da província Henrique Pereira de Lucena baixou um ato criando uma comissão composta pelo curador dos órfãos Raymundo Mendes Martins e pelos médicos Ernesto Hermelino Ribeiro e Antonio Eusébio Gonçalves de Almeida, a fim de "examinar e syndicar de todas as occurrencias que se tem dado no mesmo Asylo, indicando as faltas que forem encontradas e propondo as medidas que julgar necessarias para sanal-as" ${ }^{28}$ A notícia foi recebida pela provedoria da Santa Casa como uma afronta. No mesmo dia, o provedor oficiou ao presidente da província repudiando a comissão e alegando que os artigos $4^{\circ}, 5^{\circ}, 11^{\circ}, 13^{\circ}$ e $14^{\circ}$ do contrato firmado entre o governo e a Santa Casa estabeleciam claramente as condições em que a Santa Casa estava obrigada a prestar esclarecimentos ao governo. ${ }^{29} \mathrm{O}$ provedor logo levou ao conhecimento dos irmãos da Santa Casa a decisão do governo, em reunião da Mesa na sessão do dia 16 de outubro, que fechou questão contra a comissão e fortaleceu sua posição. ${ }^{30}$

Em 22 de outubro veio a resposta. Para Henrique de Lucena, os argumentos do provedor eram "improcedentes" e "errônea" a sua interpretação, ao supor em pé de igualdade a Santa Casa e o governo da província. Afirmava Lucena que "não há instituição ou corporação que não esteja na Província sujeita á inspecção e fiscalização do respectivo Presidente". Argumentou também que não havia, no contrato, qualquer cláusula que impedisse o governo de solicitar informações além daquelas que são obrigações da Santa Casa, como os relatórios anuais e semestrais, e que não era outra a intenção do governo se não "verificar se no Asylo se tem dado as faltas que a imprensa há denunciado e que a voz publica murmura; si a Santa Caza tem fielmente cumprido as obrigações que contrahio com a Província, e se o referido contracto deve ser mantido, alterado ou rescindido". ${ }^{31}$

Com apoio irrestrito de sua irmandade, em 31 de outubro de 1877 o provedor Francisco Rodrigues da Silva respondeu ao presidente da província que não havia, por parte da Santa Casa, nenhum interesse com relação ao caso a não ser descobrir a verdade e que "nada justificava a nomeação de uma commissão extranha contra a fé do contracto e 
prerogativas d'esta Santa Casa". Protestando contra qualquer invasão à independência da instituição que representava, disse não ser possível aceitar a comissão, já que a Santa Casa não se furtara a prestar os esclarecimentos necessários à elucidação do caso nem burlara as regras do contrato de 16 de abril de 1873, assinado entre governo e a instituição. ${ }^{32}$ Como prova de cooperação, lembrava o provedor que não se furtara ao pedido do juiz de órfãos, e que as portas do São João de Deus haviam sido franqueadas ao chefe de polícia para a realização do inquérito policial, tão logo João Japi-Assu assim ordenara.

Era verdade: as investigações no São João de Deus corriam desde que o chefe de polícia da província, Estevão Vaz Ferreira, recebera do juiz de órfãos, João Ladislau Japi-Assu, ofício ordenando que procedesse a inquérito policial sobre o caso Joanna de Sá, descobrisse quem fora o autor do "revoltante atentado" e lhe comunicasse o resultado do inquérito. ${ }^{33}$

\section{O inquérito policial}

No dia 27 de outubro de 1877 o chefe de polícia Estevão Vaz Ferreira chegou ao São João de Deus com uma equipe formada pelo amanuense da Secretaria de Segurança Fortunato Antonio de Freitas, os médicos Manuel Joaquim Saraiva e Jayme Dormund e o promotor público Raymundo Mendes Martins. Suas primeiras primeiras providências foram examinar a própria Joanna e depois sua filha Maria. No caso de Joanna, era preciso determinar se ela sofria de alienação mental com ou sem intervalos lúcidos, e assim descobrir se se achava capaz de depor. Após o exame, os peritos foram taxativos: Joanna sofria de alienação mental contínua, sofrendo de "enfraquecimento próprio as pessoas que soffrem de desordens mentaes", o que a incapacitava de prestar depoimento. Joanna foi descrita como anêmica, com flacidez muscular e constituição fraca e seu temperamento, "lymphatico", com quadro clínico de mania aguda, no qual revelavam-se "anomalias da vontade, inteligência e sensibilidade", além de "manifestas ilusões" e exacerbação da afetividade. Os médicos também perceberam que Joanna tinha uma memória quase completa, mas só até a data de sua internação. ${ }^{34}$

Depois foi a vez de Maria. Após examiná-la, tanto Manuel Saraiva quanto Jayme Dormund atestaram que, "attendendo ao desenvolvimento orgânico geral e, em particular, relativamente a certos systemas da economia, que caracterisam a edade do nascimento a termo", Maria se encontrava dentro dos padrões, ou seja, não era prematura. ${ }^{35}$

Enquanto no "rigoroso inquérito" feito pela Santa Casa um alienado foi responsabilizado pela gravidez de Joanna de Sá, no inquérito policial a responsabilidade oscilou entre dois nomes, Gustavo Pergentino Bahiano e Eduardo Carigé Baraúna. O primeiro, que se tornara suspeito por ter invadido o quarto de Joanna em episódio testemunhado por vários funcionários, era um alienado que passara dois períodos internado no São João de Deus, de 5 de setembro de 1876 a 22 de fevereiro de 1877 e de 7 de abril até sua morte, em 29 de agosto de 1877. Já o nome de Eduardo Carigé Baraúna aparece no inquérito envolto em acusações e suspeitas mais consistentes e bem mais sérias. Filho da enfermeira-chefe Emília Carigé Baraúna, várias testemunhas o acusavam, entre outras coisas, de ter livre trânsito no Asilo mesmo após o próprio diretor proibir-lhe a entrada ali, e de manter contatos por demais íntimos com algumas internas, inclusive com Joanna. 
O mau comportamento de Eduardo Baraúna foi denunciado por diversos depoentes, entre eles o ex-enfermeiro Agripino Braz Nepomuceno, que trabalhara no São João de Deus por três anos e cinco meses. Segundo Nepomuceno, o filho da enfermeira-chefe não respeitava as alienadas, "sendo por elle testemunha encontrado aos abraços e beijos com a de nome Maria da Piedade", o que foi confirmado por outro ex-funcionário, Magno Balthazar da Silveira, que sabia que "Eduardo foi encontrado pelo enfermeiro Agripino abraçando e beijando a alienada Maria da Piedade".

No caso do outro provável responsável, Gustavo Pergentino, as dúvidas quanto ao fato de ser ele pai da filha de Joanna eram muitas, e certos depoentes chegaram a inocentá-lo. O enfermeiro-chefe Manuel Tourinho foi um deles. Disse que estava almoçando no Asilo quando ele entrou no quarto de Joanna, mas que ao serem ouvidos gritos todos acudiram, "não havendo tempo para que Gustavo fizesse qualquer cousa em Joanna". Ao ser interrogada, Rosa da Silva, ex-enfermeira do São João de Deus, disse que em virtude desse incidente todos supunham ser Gustavo o pai da recém-nascida, mas que ela estava presente na ocasião e não acreditava nisso, "porquanto Gustavo quasi nada se demorou no quarto de Joanna, sendo logo visto por Emília, que gritou". ${ }^{36}$ Magno da Silveira também afirmou não ter ocorrido tempo suficiente para que Gustavo fizesse "couza alguma com Joanna", pois logo gritaram Maria Emília e a própria Joanna, "pelo que acudiram os empregados, e o levaram para o quarto onde o fecharam". ${ }^{37}$

No ofício ao provedor da Santa Casa, Demétrio Tourinho fizera uma conexão direta entre a invasão do quarto de Joanna de Sá por Gustavo e sua posterior gestação. Por sua vez, o chefe de polícia Tourinho, diante do resultado do exame do bebê, feito pelos médicos da equipe de investigação, argumentou "que si o parto tivesse sido prematuro, diria elle testemunha ser o pae da criança o alienado Gustavo Pergentino ..., mas que, considerada a data em que Joanna deu a luz, nascendo a criança a termo, tal paternidade não pode ser admissível". Informou também ter proibido Eduardo Baraúna de entrar no Asilo, por ter sido ele encontrado aos beijos e abraços com uma alienada. Com relação à mãe de Eduardo, Emília Baraúna, disse que, embora fosse pessoa de "reconhecida moralidade", não cumprira com seu dever de cuidar da alienada Joanna, a ela confiada desde sua admissão como enfermeira-chefe, em novembro de $1875 .^{38}$

Curiosamente Eduardo Baraúna não foi ouvido pelo chefe de polícia, mesmo tendo seu nome citado em quase todos os depoimentos. Só depois de o inquérito ter ido para as mãos do promotor público José Joaquim Seabra, Eduardo foi chamado a depor. Também foi chamado para prestar esclarecimentos um filho de Demétrio Tourinho, homônimo ao pai, cujo nome foi trazido à tona no depoimento de Eduardo Baraúna e dos médicos barão de Itapoan e José Antonio de Freitas, responsáveis pelos exames que confirmaram a gravidez de Joanna, feitos a pedido de Tourinho.

Eduardo Baraúna, de 25 anos, disse viver de "agenciar papeis" e mostrou-se indignado com as acusações que pesavam sobre si. Começou afirmando conhecer Joanna "desde que ella morava no Rosário em casa de seu pae, havia mais ou menos oito annos", e que sabia do seu parto no Asilo por ter ouvido de uma escrava pertencente a outra alienada e também por ter lido o inquérito policial. ${ }^{39}$ Seu interesse pelo inquérito viera por saber que a ele pretendiam imputar a paternidade da criança, e a partir de então tratou de pesquisar para 
ver se descobria o autor de tão "infame crime". Nas investigações particulares de Eduardo, o primeiro suspeito que lhe chegou aos ouvidos foi justamente o do ex-diretor do Asilo, Demétrio Cyriaco Tourinho. Depois as suspeitas se reverteram para o filho de Demétrio Tourinho, a quem Eduardo acusou de ter fugido para o Rio de Janeiro, "deixando a sua casa de negocio e interesses n'esta capital" e casando-se logo em seguida com uma quase desconhecida. Eduardo Baraúna não apresentou o motivo de sua suspeição sobre pai e filho, mas afirmou que, ao correr a notícia da gravidez de Joanna, as suspeitas recaíram logo sobre o filho de Demétrio. Afirmou que sua mãe conversara com o ex-diretor do Asilo ao final de julho, sobre a suspeita de gravidez, ao que ele respondera que já sabia do que estava acontecendo e que "quando nascesse a creança seria levada para a casa dos expostos da Misericordia".

O silêncio de Demétrio sobre a gravidez de Joanna foi interpretado por Eduardo como sinal de "falta de força moral ou desejo de encobrir o crime, por ver n'elle compromettida pessoa sua". Eduardo disse que também suspeitava do farmacêutico Arthur Raul Pinheiro, que tinha precedentes que o incriminavam. Perguntado por Seabra quais seriam esses precedentes, disse que o farmacêutico havia convidado a alienada Maria Emília para atos ilícitos e até lhe oferecera mil réis em troca, além de ter tido cópula carnal com uma outra interna de nome Luiza. Mais ainda: que sua mãe presenciara um beijo dado pelo farmacêutico na alienada Maria Cândida, durante uma refeição no Asilo. Assegurou que todos sabiam desses fatos que envolviam o farmacêutico e algumas alienadas, inclusive Tourinho, que soube através de sua mãe mas nada fez a respeito. Quanto às acusações que pesavam contra ele, disse que os empregados do Asilo eram seus inimigos e de sua mãe, porque ambos não toleravam os "actos inconvenientes" que eles praticavam, e que nunca teve sua entrada e permanência no Asilo proibida pelo ex-diretor, que chegava até a convidálo a pernoitar no São João de Deus quando lá também se encontrava.

Depois de Eduardo Baraúna, chegou a vez de Demétrio Tourinho filho depor e apresentar sua defesa. Em depoimento rápido, disse que não sabia da gravidez de Joanna e que só soube que ela havia dado à luz uma criança depois de estar morando no Rio de Janeiro, para onde fora tratar de seus negócios. Para ele não passavam de "calunia e injuria" as acusações de Eduardo, que até dissera a seu irmão que "havia de empurrar a auctoria de tal facto para alguém - fosse quem fosse". Confirmou que seu pai proibira a entrada de Eduardo no Asilo devido a seu péssimo procedimento com as alienadas e afirmou que nunca soube de nada que desabonasse a reputação do farmacêutico Raul Pinheiro.

Eduardo mostrou-se mais indignado ainda após o depoimento de Demétrio filho. Disse que ele não merecia fé, pois tinha interesse na questão que envolvia o pai, além de ser seu inimigo pessoal. Segundo Eduardo, tudo o que Demétrio dizia era resultado de ordem paterna, que Tourinho obrigara tanto o filho quanto os empregados do Asilo a mentirem nos seus depoimentos e que guardava para "logar competente" sua defesa, quando apresentaria provas exuberantes a respeito do valor do depoimento de todas as testemunhas.

O lugar competente acabou sendo as páginas de $O$ Monitor, que continuava a abrir espaço para o caso. No dia 13 de dezembro de 1877 Eduardo Baraúna teve a chance de assinar um editorial, no qual afirmava ter sua consciência tranqüila e pedia direito de defesa depois de ter sido tão caluniado por aqueles com quem "estava mais strictamente 
ligado pelos vínculos d'amizade". Na verdade a defesa de Eduardo consistiu em mais ataques à família Tourinho, sobretudo a Demétrio pai, como por exemplo o fato de ter ele forçado os empregados do São João de Deus e o próprio filho a mentirem em seus depoimentos, chegando a levar os empregados à sua casa para tramarem um plano que reputasse a ele, Eduardo, a culpa pela gravidez de Joanna. Repetiu que os empregados do Asilo o odiavam e a sua mãe por terem sempre denunciado ao ex-diretor as "immoralidades" que ocorriam no São João de Deus, como "enfermeiros namorando loucas e outros amaziados com enfermeiras", e que a instituição "tinha de asylo simplesmente o nome". Eduardo sentiase magoado por ver Tourinho, que tantas vezes se mostrou seu amigo, transformado em seu mais "audaz perseguidor", e concluía, em tom de forte apelo emocional, dizendo saber por que ele era o homem perfeito para servir de bode expiatório no caso: "orphão, sem protecção, sem verdadeiros amigos, pobre, humilde, filho de uma viuva, desafecto dos empregados do Asylo; quem melhor para ser atado ao poste da calumnia, para ser apontado como o auctor do monstruoso crime perpetrado contra uma infeliz privada das luzes da razão". ${ }^{40}$

\section{Cai o pano}

Assim como irrompeu abruptamente nas páginas do diário, o nome de Joanna de Sá desapareceu de $O$ Monitor junto com o ano de 1877. As últimas notícias sobre o caso publicadas no jornal foram apenas mais dois editoriais de Eduardo Baraúna, 14 e 15 de dezembro, nos quais o rapaz prosseguia com as mesmas denúncias e acusações contra Demétrio Tourinho pai e filho. Com a virada do ano, o jornal não mais divulgou nenhuma notícia sobre os desdobramentos do caso. O inquérito policial foi encerrado em 19 de novembro de 1877, e o chefe de polícia deu as investigações por concluídas, dizendo estar certo de que Joanna Virgínia Autran e Sá havia tido "copula carnal" no asilo São João de Deus e apontando como principal suspeito Eduardo Baraúna. Entretanto, diz Vaz Ferreira, nenhuma das testemunhas afirmava categoricamente ser ele o autor do delito. ${ }^{41}$ É provável que o inquérito tenha sido arquivado devido à fragilidade de suas conclusões.

A briga entre a Santa Casa e o governo da província acabou assim que mudou a direção dos ventos da política. Com a queda do Partido Conservador, em janeiro de 1878, Henrique de Lucena foi exonerado do cargo de presidente da província por decreto do dia 19 do mesmo mês. Assumiu Francisco Ignácio Marcondes Homem de Mello, do Partido Liberal, nomeado por carta imperial de 19 de janeiro. Homem de Mello oficiou ao provedor da Santa Casa em 20 de maio pondo fim à crise entre aquela instituição e o governo e encerrando a querela em torno da comissão que fiscalizaria o São João de Deus. Afirmou que Lucena excedera-se no exercício do poder e cancelou a fiscalização no São João de Deus, demonstrando uma enorme boa vontade em manter as boas relações com a Santa Casa de Misericórdia. ${ }^{42}$

Enquanto a Santa Casa e o governo da província não se entendiam sobre a fiscalização no São João de Deus e o inquérito policial ouvia mais de trinta testemunhas, na tentativa de descobrir quem era o pai da menina Maria, a principal personagem do caso permanecia envolta em silêncio, ainda que o provedor da Santa Casa, "conquanto seja sabido o que 
vale, perante sciencia e a Justiça, o testemunho dos loucos"43, tenha tentado conversar com Joanna sobre o ocorrido. Foi nesse silêncio que Joanna Sá morreu no São João de Deus, em 3 de outubro de 1887. Não foi possível obter a causa da morte de Joanna nem onde foi sepultada. Seu falecimento consta do relatório da Santa Casa de julho de 1888, no qual o provedor comunica que foram cobradas do inventariante do espólio a quantia de $126 \$ 400$, referentes a débitos vencidos. ${ }^{44}$ No seu inventário constam como herdeiros sua irmã Maria Amália de Sá e Silva, do segundo casamento de seu pai; seus sobrinhos Jardelina, João e Manoel, filhos de seu irmão Jacintho Alves Autran e Sá; e Maria Antonieta e Maria Carolina, filhas de sua irmã Gertrudes Autran e Sá, já falecidos. A herança somava 9:240\$869 réis em apólices da Caixa Econômica e da Tesouraria Geral, além de terrenos situados no Forte de São Pedro e Ladeira da Fonte, avaliados em $932 \$ 950 .{ }^{45}$

\section{NOTAS}

* Este artigo baseia-se em parte da dissertação intitulada Equilíbro distante: a mulher, a medicina mental e o asilo. Bahia: 1874-1912, apresentada em 2005 à Universidade Federal da Bahia.

${ }^{1}$ Inauguração do Asylo de Alienados de São João de Deus, Gazeta Medica da Bahia, Bahia, n.167, p.376, 1874.

${ }^{2}$ Livro de Atas da Mesa, n.19, 1874, p.1, Arquivo da Santa Casa de Misericórdia da Bahia.

${ }^{3}$ Relatório apresentado pelo provedor Cons. Manuel Pinto de Souza Dantas em 1875, Salvador, Typographia do Diario da Bahia, 1875, Arquivo da Santa Casa de Misericórdia da Bahia.

${ }^{4}$ Segundo Harris (1993), Pinel definia a mania como uma confusão mental restrita, na qual o doente dominava o raciocínio a respeito de certos assuntos, ao mesmo tempo que apresentava incoerência e extrema excitação sobre outros, sendo assim uma loucura localizada. O conceito foi ampliado na concepção das monomanias, idéias fixas a respeito dos mais variados objetos. Ver também Albuquerque, 1858.

${ }^{5}$ Para a história do São João de Deus ver Jacobina, 2001 e Bastos, 1985.

${ }^{6}$ Jornal O Monitor, 31 out. 1877, p.1. Este e os demais números de O Monitor cujas matérias são aqui mencionadas encontram-se na Seção de Microfilmes da Biblioteca Central da Bahia.

${ }^{7}$ Visíveis no Livro de Registro de Correspondência com o Asilo São João de Deus, n.114, 1876, p.87, Arquivo da SCMBa.

${ }^{8}$ O Monitor, 10 out. 1877 , p.1.

${ }^{9}$ O Monitor, 11 out. 1877, p.1.

${ }^{10}$ Amâncio João Cardoso de Andrade, médico adjunto, pediu demissão em 30 de agosto de 1877. (Cf. Livro de Registro de Correspondência com o Asilo São João de Deus, n.114, 1877, p.53v, Arquivo da SCMBa).

${ }^{11}$ O pedido de demissão do médico diretor Demétrio Cyriaco Tourinho encontra-se na Seção Colonial e Provincial do Arquivo Público do Estado da Bahia (Apeba), maço 5.287.

${ }^{12}$ De fato, reconhecendo o empenho de Demétrio Tourinho na condução do Asilo São João de Deus, a Santa Casa registrou, em ata na sessão da Mesa de 20 de fevereiro de 1877, um voto de "louvor e confiança" ao médico diretor, "pelos bons serviços prestados ao Asylo de São João de Deus, do qual é seu digno director, e que se testemunhe a $V^{a} S^{a}$ seu reconhecimento por esses serviços" (cf. Livro de Registro de Correspondência com o Asilo São João de Deus, n.114, 1877, p.45, Arquivo da SCMBa).

${ }^{13}$ Livro de Registro de Correspondência com o Asilo São João de Deus, n.114, p.53, Arquivo da SCMBa. 1877.

${ }^{14}$ Casado com Gertrudes Autran de Sá Gouveia, irmã de Joanna.

${ }^{15}$ Carta confidencial do médico Henrique Autran da Matta e Albuquerque ao presidente da província Henrique Pereira de Lucena. Seção Colonial e Provincial, 17 set. 1877, maço 5.287, Apeba. 
${ }^{16}$ Regulamento Geral Provisório, artigos 103 e 105. Livro sobre a Fundação do Asilo de Alienados de S. João de Deus, n.157, p. 107-108, 1874, Arquivo da SCMBa.

${ }^{17}$ Inventário 04/1666/2136/07, Seção Judiciária da Apeba.

${ }^{18}$ Maço 5.287, 1877, Seção Colonial e Provincial da Apeba.

${ }^{19}$ Ofício do presidente da província Henrique Pereira de Lucena ao provedor da Santa Casa Francisco Rodrigues da Silva, 1877, maço 5.287, Seção Colonial e Provincial da Apeba.

${ }^{20}$ Nem tanto: preocupado com a moralidade e atento ao que poderia acontecer, Demétrio Tourinho solicitou, no relatório apresentado ao provedor em 30 de junho de 1875 e naquele de 30 de junho de 1876, a construção de novos pavilhões para que fossem separados homens e mulheres (cf. relatório apresentado pelo provedor cons. Manuel Pinto de Souza Dantas, 1875, p.7, Arquivo da SCMBa).

${ }^{21}$ Ofício enviado pelo diretor ao mordomo do asilo Sâo João de Deus, Seção Colonial e Provincial, maço 5.287, Apeba.

22 Ofício do provedor da Santa Casa Francisco Rodrigues da Silva ao presidente da província Henrique Pereira de Lucena, 1877, maço 5.287, Seção Colonial e Provincial da Apeba.

${ }^{23}$ Livro de Registro de Correspondência dos Reservados, n.147, 1877, p.4v-5, Arquivo da SCMBa.

${ }^{24}$ Ofício do provedor da Santa Casa Francisco Rodrigues da Silva ao barão de Itapuã, 22. set. 1877, Seção Colonial e Provincial, maço 5.287, Apeba.

${ }^{25}$ Como indicado na nota 21, tanto no relatório apresentado ao provedor em 30 de junho de 1875 quanto no de 30 de junho de 1876, Demétrio Tourinho pedira a construção de novos pavilhões, para que fossem separados homens e mulheres. Segundo Tourinho, essa separação já era feita "quanto é possível" e os novos pavilhões "ainda mais separarão um sexo do outro" (Relatório apresentado pelo provedor Cons. Manuel Pinto de Souza Dantas em 1875, Salvador, Typographia do Diario da Bahia, 1875, p.7).

${ }^{26}$ Note-se que a sexualidade incontida é vista, aqui, como um atributo dos destituídos da razão. Em linha semelhante, o excesso de erotismo também era visto como sintoma de alienação mental.

${ }^{27}$ Ofício do provedor da Santa Casa de Misericórdia para o presidente da província da Bahia, 1877, Seção Colonial e Provincial, maço 5.287, Apeba. No mesmo dia o provedor comunicou ao juiz de órfãos o nascimento da filha de Joanna (cf. Livro de Registro de Correspondência dos Reservados, n.147, 1877, p.5v-5, Arquivo da SCMBa).

${ }^{28}$ Ato da Presidência da Província, 13 out. 1877, Seção Colonial e Provincial, maço 5.287, Apeba.

${ }^{29} \mathrm{No}$ artigo $4^{\circ}$ estabelecia-se a independência econômica e administrativa da Santa Casa; nos artigos $5^{\circ}$ e $11^{\circ}$, a obrigatoriedade da apresentação de um relatório semestral pela Santa Casa, sendo direito do governo pedir informações adicionais, caso julgasse necessário; e os $13^{\circ}$ e $14^{\circ}$ artigos prescreviam que tanto o governo quanto a Santa Casa estavam de comum acordo quanto ao mesmo contrato.

${ }^{30}$ Livro de Atas da Mesa, n.20, p.22, Arquivo da SCMBa.

${ }^{31}$ Oficío do presidente da província da Bahia para o provedor da Santa Casa de Misericórdia, 1877, maço 5.287, Seção Colonial e Provincial da Apeba.

32 Oficío do provedor da Santa Casa de Misericórdia para o presidente da província da Bahia, 1877, maço 5.287, p.117v, Seção Colonial e Provincial da Apeba.

33 Ofício do juiz de direito da vara especial dos órphãos e ausentes da capital da Bahia, transcrito no jornal O Monitor, 27 nov. 1877, p.1.

${ }^{34}$ O Monitor, 27 nov. 1877, p.1.

${ }^{35}$ Mesmo tendo nascido a termo, Maria não resistiu a uma inflamação intestinal e faleceu em 3 de dezembro, segundo informou seu tio e tutor ao provedor da Santa Casa Antonio Gouveia (cf. Livro $1^{\circ}$ de Registro com as Autoridades, n.101, p.122, Arquivo da SCMBa.

${ }^{36}$ O Monitor, 27 nov. 1877, p.1.

${ }^{37}$ O Monitor, 29 nov. 1877, p.1.

${ }^{38}$ O Monitor, 30 nov. 1877, p.1.

${ }^{39} \mathrm{O}$ depoimento de Eduardo Baraúna foi publicado no jornal O Monitor em 12 de dezembro de 1877, tendo o inquérito sido encerrado no dia 19 daquele mês.

${ }^{40}$ O Monitor, 13 dez. 1877, p.2. 
${ }^{41}$ O Monitor, 30 nov. 1877, p.1.

${ }^{42}$ Relatório apresentado pelo provedor Francisco Rodrigues da Silva em 1878, Salvador, Typographia do Diario da Bahia, 1875, Arquivo da SCMBa.

43 Ofício do provedor da Santa Casa de Misericórdia para o presidente da província da Bahia, 1877, maço 5.287, Seção Colonial e Provincial da Apeba.

${ }^{44}$ Relatório apresentado pelo provedor substituto João Bernardino Franco Lima em 1888, Bahia, LithoTypographia de João Gonçalves Tourinho, 1888, p.51-52, Arquivo da SCMBa.

${ }^{45}$ Inventário 03/1725/12, Seção Colonial e Provincial da Apeba.

\section{REFERENCIAS}

ALBUQUERQUE, Francisco Julio Freitas e. Dissertação sobre a monomania. Bahia: Typographia do Diario da Bahia. 1858.

BASTOS, Sérgio Borges.

$O$ asilo de alienados S. João de Deus, 1874-1912.

Dissertação (Mestrado em Saúde Comunitária)

- Universidade Federal da Bahia, Salvador. 1985.

CUNHA, Maria Clementina Pereira.

O espelho do mundo: Juquery, a história de um asilo. São Paulo: Paz e Terra. 1986.

ENGEL, Magali.

Psiquiatria e feminilidade. In: Del Priore, Mary (Org.). História das Mulheres no Brasil. São Paulo: Contexto. p.322-361. 2001.

GARCIA, Carla Cristina.

Ovelhas na névoa: um estudo sobre as mulheres e a loucura. Rio de Janeiro: Rosa dos Tempos. 1995.
HARRIS, Ruth.

Assassinato e loucura: medicina, leis e sociedade no fin de sciècle. Rio de Janeiro: Rocco. 1993.

JACOBINA, Ronaldo Ribeiro.

A prática psiquiátrica na Bahia (1874-1974): estudo histórico do Asilo de São João de Deus/ Hospital Juliano Moreira. Tese (Doutorado) Escola Nacional de Saúde Pública, Fundação Oswaldo Cruz, Rio de Janeiro. 2001.

MARTINS, Ana Paula Vosne. A medicina da mulher: visões do corpo feminino na constituição da obstetrícia e da ginecologia no século XIX. Tese (Doutorado em História) Universidade Estadual de Campinas, Campinas. 2000.

VIEIRA, Elisabeth Meloni.

A medicalização do corpo feminino. Rio de Janeiro: Editora Fiocruz. 2002.

\section{$\rightarrow \rightarrow \rightarrow<<<$}

